\title{
Perianal Basal Cell Carcinoma
}

\author{
Isil Bulur $^{\mathrm{a}}$ Emine Boyuk $^{\mathrm{a}}$ Zeynep Nurhan Saracoglua ${ }^{\mathrm{a}}$ Deniz Arik ${ }^{\mathrm{b}}$ \\ Departments of ${ }^{\mathrm{a}}$ Dermatology and Venereology and ${ }^{\mathrm{b}}$ Pathology, Faculty of Medicine, \\ Osmangazi University, Eskişehir, Turkey
}

\section{Key Words}

Basal cell carcinoma $\cdot$ Perianal $\cdot$ Local resection

\begin{abstract}
Basal cell carcinoma $(B C C)$ is the most common non-melanoma skin cancer. Exposure to ultraviolet light is an important risk factor for BCC development and the disorder therefore develops commonly on body areas that are more exposed to sunlight, such as the face and neck. It is uncommon in the closed area of the body and quite rare in the perianal and genital regions. Herein, we report a 34-year-old patient with perianal BCC who had no additional risk factors.

(c) 2015 S. Karger AG, Basel
\end{abstract}

\section{Introduction}

Basal cell carcinoma (BCC) is a common skin tumor that constitutes $75 \%$ of nonmelanocytic skin tumors. More than $80 \%$ of BCC cases are localized in areas exposed to the sun, such as the head and neck [1]. The most important etiological factor is exposure to ultraviolet light, while other risk factors include advanced age, male gender, immunosuppression and arsenic exposure. BCC can also develop on areas of chronic inflammation, burn scars, squamous cell cancer and ulcers $[1,2]$. It is quite rare in areas with no ultraviolet exposure, especially the genital and perianal regions. We present a patient with a condylomalike tumoral mass diagnosed as BCC.

\section{Case Presentation}

A 34-year-old male presented with a bleeding perianal mass that had been growing for the last 6 months. There was nothing of significance in the personal or family history 
Bulur et al.: Perianal Basal Cell Carcinoma

and especially no history of anogenital warts, sexually transmitted disease, malignancy, inflammatory dermatosis or arsenic exposure. Dermatology examination revealed an exophytic condyloma-like nodular lesion approximately $3 \times 6 \mathrm{~cm}$ in size with surface ulceration in the left lateral perianal region and no other pathological findings on whole body examination (fig. 1). Laboratory test values were normal and the HIV, HSV and syphilis serology results were negative. Histopathological evaluation of a punch biopsy obtained from the lesion showed an edematous stroma containing mononuclear inflammatory cells under a stratified squamous epithelium with epithelial cell islands containing pleomorphic cells and showing infiltrative growth and tumor cell islands with peripheral palisading (fig. 2a). The tumor cells had a pleomorphic character, with a large vesicular nucleus and narrow cytoplasm (fig. 2b). The histopathology result was superficial BCC and total excision was suggested for treatment. Histopathological examination of the total excision material was also found to be consistent with superficial BCC. We did not detect any recurrence during the follow-up of 8 months.

\section{Discussion}

Perianal BCC is an uncommon skin tumor in dermatology practice. BCC is seen at a rate of $0.2 \%$ among all anorectal cancers and about $1 \%$ of all BCC cases are located in the perianal region [3, 4]. A review of the literature reveals that the disorder is more common in males, with a mean age of 73 years [3]. The etiopathogenesis includes chronic trauma such as itching, chronic dermatitis, nevoid BCC syndrome, p53 mutation, immune deficiency, sexually transmitted disease and arsenic exposure $[3,5]$. In contrast to squamous cell carcinoma, perianal BCC cases do not show HPV positivity [6]. We did not find any other BCC lesions in our patient by whole body examination, and the trigger factors of disease development were not detected. The differences between the perianal BCC in our patient and those reported in the literature is the early age and lack of known risk factors, indicating that our patient's disease developed on a background of genetic predisposition via the sonic hedgehog pathway.

The differential diagnosis of perianal BCC includes condyloma acuminatum, Bowen's disease, Paget's disease and squamous cell carcinoma. It is important to distinguish perianal basaloid (cloacogenic) squamous cell tumors because of their aggressive course and early metastatic potential [7]. The typical palisading appearance and the presence of Ber-EP4 monoclonal antibody expression indicate a diagnosis of perianal BCC [7, 8]. Patil et al. [8] emphasized that a lack of tumor retraction artifact and atypical mitotic figures on histopathology as well as the presence of strong Ber-EP4 and BCL2 staining on immunohistochemical evaluation indicate BCC. HPV positivity and p16INK4a upregulation can be present in anal squamous cell carcinomas, but HPV has been shown not to play a role in perianal BCC etiopathogenesis $[9,10]$. The BCC diagnosis in our patient was made with the typical histopathological findings and HPV assessment was found to be negative.

The most common perianal BCC type is nodular BCC $[3,8]$, whereas our patient was diagnosed as superficial BCC. A literature review revealed that Gibson and Ahmed [3] had observed the superficial type as the second most common type at a rate of $18 \%$ among perianal and genital region BCC cases, and that Patil et al. [8] had found one nodular/superficial and one superficial BCC case among the nine perianal BCC lesions that they had evaluated histopathologically.

BCC rarely metastasizes while perianal BCC can have an aggressive course and show more frequent metastasis [7]. Local excision is frequently recommended for BCC treatment, 
Bulur et al.: Perianal Basal Cell Carcinoma

but cryotherapy, radiotherapy, immunotherapy, electrodestruction, photodynamic therapy, immunotherapy, retinoids and chemotherapy are other treatment options when excision is not possible [3]. We achieved cure with total excision of the lesion in our patient, and new lesion development was not observed during 8 months.

\section{Conclusion}

Perianal BCC cases are diagnosed later than other types and can be mistakenly treated as inflammatory or infectious lesions. Histopathological evaluation of perianal region lesions is therefore quite important. We also want to emphasize that local excision treatment at the early stage following an accurate diagnosis is effective in ensuring cure without advanced treatments.

\section{References}

1 Hauschild A, Breuninger H, Kaufmann R, Kortmann RD, Schwipper V, Werner J, Reifenberger J, Dirschka T, Garbe C: Short German guidelines: basal cell carcinoma. J Dtsch Dermatol Ges 2008;6(suppl 1):S2-S4.

-2 Kwasniak LA, Garcia-Zuazaga J: Basal cell carcinoma: evidence-based medicine and review of treatment modalities. Int J Dermatol 2011;50:645-658.

-3 Gibson GE, Ahmed I: Perianal and genital basal cell carcinoma: a clinicopathologic review of 51 cases. J Am Acad Dermatol 2001;45:68-71.

4 Leonard D, Beddy D, Dozois EJ: Neoplasms of anal canal and perianal skin. Clin Colon Rectal Surg 2011;24: 54-63.

5 Park J, Cho YS, Song KH, Lee JS, Yun SK, Kim HU: Basal cell carcinoma on the pubic area: report of a case and review of 19 Korean cases of BCC from non-sun-exposed areas. Ann Dermatol 2011;23:405-408.

-6 Kreuter A, Bechara FG, Stücker M, Brockmeyer NH, Altmeyer P, Wieland U: Perianal basal cell carcinoma unusual localization of a frequent tumor. J Dtsch Dermatol Ges 2012;10:59-61.

7 Damin DC, Rosito MA, Gus P, Tarta C, Weindorfer M, Burger MB, Cartell A: Perianal basal cell carcinoma. J Cutan Med Surg 2002;6:26-28.

8 Patil DT, Goldblum JR, Billings SD: Clinicopathological analysis of basal cell carcinoma of the anal region and its distinction from basaloid squamous cell carcinoma. Mod Pathol 2013;26:1382-1389.

-9 Wieland U, Ritzkowsky A, Stoltidis M, Weissenborn S, Stark S, Ploner M, Majewski S, Jablonska S, Pfister HJ, Fuchs PG: Communication: papillomavirus DNA in basal cell carcinomas of immunocompetent patients: an accidental association? J Invest Dermatol 2000;115:124-128.

10 Escutia B, Ledesma E, Serra-Guillen C, Gimeno C, Vilata JJ, Guillén C, Nagore E: Detection of human papilloma virus in normal skin and in superficial and nodular basal cell carcinomas in immunocompetent subjects. J Eur Acad Dermatol Venereol 2011;25:832-838. 


\section{Case Reports in Dermatology}

\begin{tabular}{l|l}
\hline Case Rep Dermatol 2015;7:25-28 \\
\hline DOI: 10.1159/000380847 & $\begin{array}{l}\text { C 2015 S. Karger AG, Basel } \\
\text { www.karger.com/cde }\end{array}$ \\
\hline
\end{tabular}

Bulur et al.: Perianal Basal Cell Carcinoma

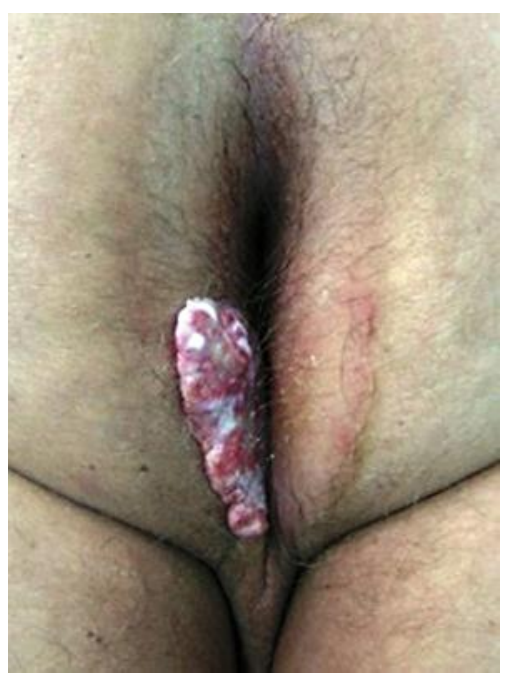

Fig. 1. Exophytic nodular lesion approximately $3 \times 6 \mathrm{~cm}$ in size with surface ulceration in the left lateral perianal region.
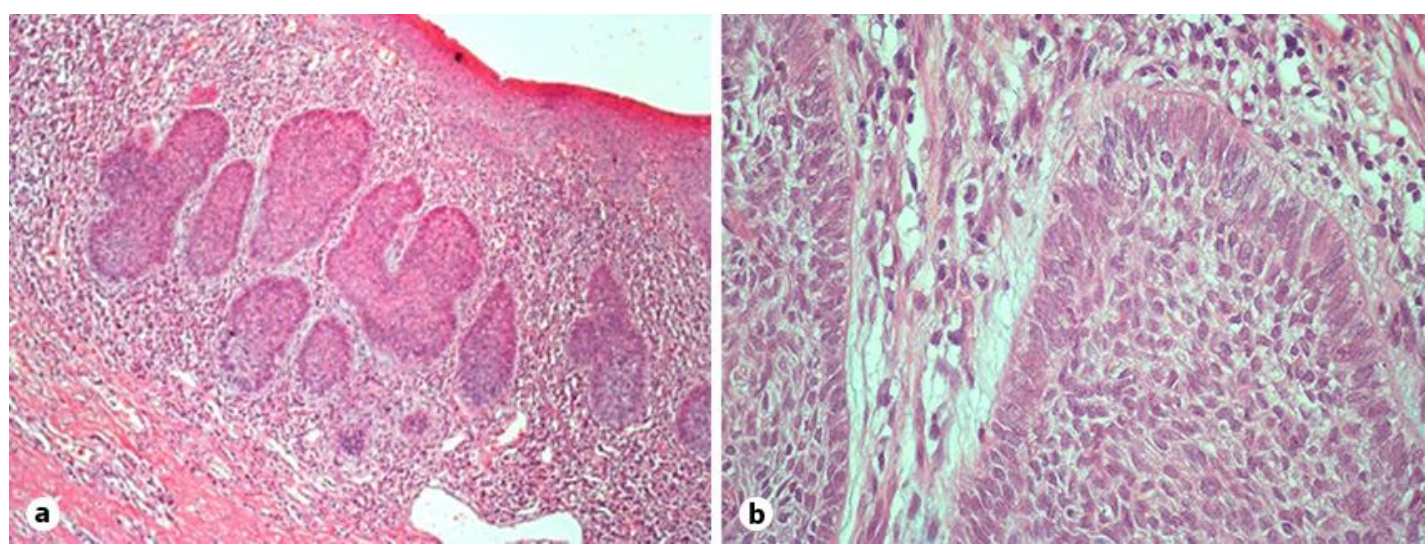

Fig. 2. a Edematous stroma, mononuclear inflammatory cells, stratified squamous epithelium with epithelial cell islands containing pleomorphic cells and showing infiltrative growth and tumor cell islands with peripheral palisading. HE, $\times 40$. $b$ The tumor islands with peripheral palisading. The tumor cells had a pleomorphic character with a large vesicular nucleus and narrow cytoplasm. HE, $\times 400$. 